\title{
Application of FOPID Design for LFC Using Flower Pollination Algorithm for Three-Area Power System
}

\author{
D. K. Sambariya ", Omesh Nagar, Aswant Kumar Sharma \\ Department of Electrical Engineering, Rajasthan Technical University, Kota, India \\ Received December 25, 2019; Revised February 18, 2020; Accepted February 24, 2020
}

Copyright $\odot 2020$ by authors, all rights reserved. Authors agree that this article remains permanently open access under the terms of the Creative Commons Attribution License 4.0 International License

\begin{abstract}
In power system, frequency is one of the main factor which affects the A.C. system. In order to maintain the performance of the system, frequency need to be controlled on the generation part as well as load side. In this paper, fractional order PID (FOPID) controller is designed for the three-area load frequency control (LFC) in an interrelated power system (PS) in MATLAB simulation. The LFC of generating units have used in frequency control of the dissolute response in the power system. FOPID controller parameters are intended using the Flower Pollination Algorithm (FPA) for the minimize error. The prototype of generating units with FOPID controller is simulated in MATLAB/SIMULINK platform. In this study, simulation researches on a three-area LFC with different generating units are considered. The objective function is the minimization of the Integral Squared Error (ISE) for the optimum strategy of FOPID parameters. These results presented that the FOPID controller was vital to the parameter variations in the considered system. The simulation results specialized much better performance of FOPID controller for LFC in comparison with other FOPID controllers available in the literature. FPA-FOPID Controller in the system as compared to the existing ICA-FOPID and GA-FOPID controller in literature. The result shows that the FPA result outperforms as compared with other results.
\end{abstract}

Keywords Fractional Order Proportional Integral Derivative (FOPID), Load Frequency Control (LFC), Automatic Voltage Regulator (AVR)

\section{Introduction}

The LFC is a significant part of working and regulatory of the power system in large network connected to the tie-lines. The LFC problems of a power system are chanced due to the disturbing of generation power. It is well recognised that the real purpose of a power operator is to preserve the system frequency within the minimal values 49.9 to $50.1 \mathrm{~Hz}$ in the case of India.

Distribution, transmission and generation are part of the power system. Large interrelated number of fundamentals results to a complex power system which is normally connected to the tie-lines. In the present time, it is becoming a tough mission to engineers for continuing the improved power demand from the recent power system. The safe and consistent process of a large interrelated three area power system needs the corresponding between the load demand and generating power.

Sambariya, 2017 [1-3] have presented the EHO technique for the application of LFC and tuning the PID parameters. Shayeghi, 2016 [4] have proposed the work of SSO technique-based tuning of the FOPID parameters. The power system for LFC is also met the generation and load demand by optimally planned [1]. The real process, electric energy supplied by the LFC for a power system with insignificant frequency and terminal voltage. It is excited to efficient constant operation of the power system by sustaining frequency and essential tolerances frequency deviation are also diminished by considered FOPID controller.

FOPID has a better performance by comparing the conventional PID controller. FOPID have five parameters such as $K_{P}$ is a proportional gain, $K_{I}$ is integral gain, $K_{D}$ is derivative gain, $\lambda$ is integral order and $\mu$ is differential order, FOPID controller gives better flexibility and better response compare the conventional PID controller. PID has a non-integer order controller where's the FOPID controller is an improved form of PID controller by converting the integer order of derivative \& integrator into the fractional-order [5-7].

Debbarma, 2016 [8] have presented the FPA technique for the application of LFC and tuning the FOPID parameters. Gupta, 2015 [9] have reported the TimeResponse Specification Based Fitness and FOPID parameters are tuned by the PSO Algorithm. The power 
system controlling is also the highest exciting problem for controller designers. In power systems, objectives are to control the output power of generating units and so that the deviation of transient frequency in specific areas. Chiranjeevi, 2014 [10] have reported the LFC system for interconnected PS and FOPID parameters are tuned by the PSO technique. Yang, 2012 [11] have presented the FPA technique. Alyasseri, 2018 [12] have presented the FPA technique and tuned the FOPID parameters. The switched power between persist zone within the stated parameters and steady-state error zero are also called the LFC $[2,8]$.

Taher, 2014 [13] have proposed the work of Imperialist Competitive Algorithm (ICA) and the FOPID parameters are tuned by the ICA technique. Bayati, 2015 [14] have reported the LFC system for the interrelated PS and also used the integer-order PID controller. FOPID parameters are tuned by the GA technique. To hold the frequency and Tie-line power deviation within the acceptable limits for different operating conditions and load demand for the LFC problem is preferred. For tuning of the FOPID controller with the help of regression model can be implemented for AVR system in state-space tuning for weapon system [4]. It has a postponement thought $d^{\alpha} y(\mathrm{t}) / \mathrm{dt}^{\alpha} \quad$ non-integer number of $\alpha$ and $d^{n} y(\mathrm{t}) / \mathrm{dt}^{n}$ an integer number of $\mathrm{n}$. It has differential equations of non-integer order of dynamic system called fractional-order system $[9,15]$.

This paper also described the FOPID controller parameters are tuned by the FPA technique. The proposed FOPID controller according to FPA technique improved the dynamic performance of variation in frequency. FPA gives a better solution as compared to the Genetic
Algorithm and Imperialist Competitive Algorithm.

This paper is divided into five sections. The II section denoted the problem formulation with an introduction to the measured the power system along with the basics of FOPID controller and objectives functions. Section III gives the idea of Flower Pollination Algorithm FPA. Section IV shows the comparisons and simulation results. Section V is of the conclusion followed with references.

\section{Problem Formulation}

\subsection{System Description}

Hydropower plant basically has four ways: Generator, Turbine, Penstock and Electric-hydraulic servo system. When the steam Turbine is also controlled then The LFC is controlled and the steam valve is open or close.

In three areas, LFC has a three-different power plant interrelated to each other and the tie-lines. One and second is the thermal plant and the other one is the hydro plant. In each three-area, power systems are also different power plants. The hydro turbine is circling to the potential vigour of the water flow [3].

In three areas, LFC of thermal-hydro plants can be interrelated complete the tie lines. The main impartial is to control the frequency of each power plant or tie line. The thermal-hydro power plant contains such as speed governor, hydro turbine, non-reheat turbine, reheat turbine, re-heater and generator. The model of the transfer function block of generating units as presented in Figure 1 [14].

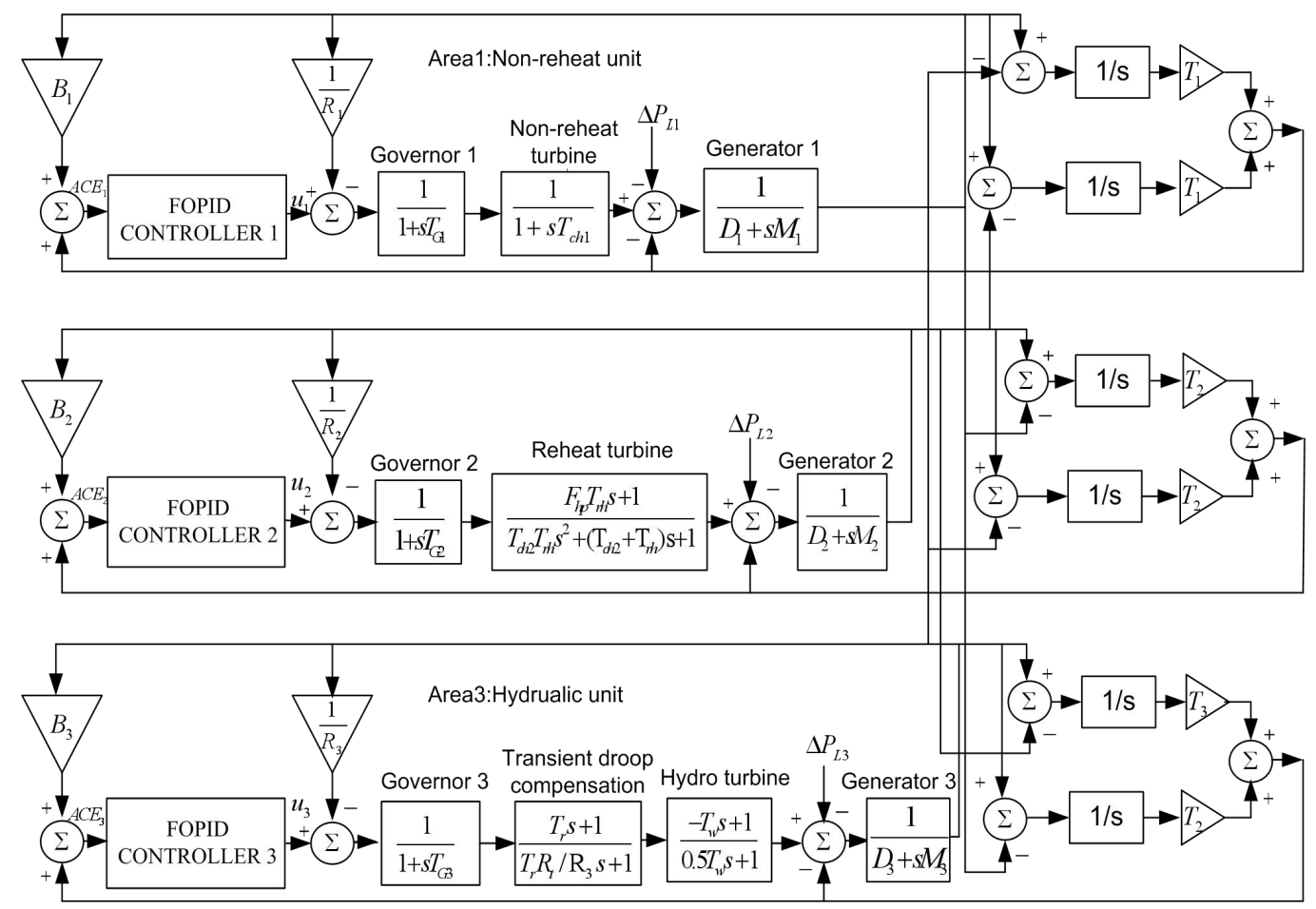


Figure 1. Three-area power system with different generating units

\subsection{Fractional Calculus}

The Riemann- Liouville and the Grunwald Ltnikov definition are also used in universal fractional differentiation and integral Eq. 1 and 2 [8] respectively.

$$
\begin{gathered}
{ }_{\alpha} D_{t}^{\alpha} f(\mathrm{t})=\frac{1}{\int(\mathrm{n}-\alpha)} \frac{d^{n}}{d t^{n}} \int \frac{f(\tau)}{(\mathrm{t}-\tau)^{1-(\mathrm{n}-\alpha)}} \cdot d \tau \\
{ }_{\alpha} D_{T}^{\alpha} f(\mathrm{t})=\lim _{h=0} \frac{1}{\int(\alpha) \mathrm{h}^{\alpha}} \sum_{k=0}^{[(\mathrm{t}-\alpha) / \mathrm{h}]} \frac{\int(\alpha+k)}{\int(\mathrm{k}+1)} f(\mathrm{t}-\mathrm{kh})
\end{gathered}
$$

By taking the Laplace of Eq. 1 and 2

$$
\begin{gathered}
L\left\{{ }_{\alpha} \mathrm{D}_{t}^{\alpha} \mathrm{f}(\mathrm{t})\right\}=\mathrm{s}^{\alpha} F(\mathrm{~s})-\left.\sum_{k=0}^{n-1} s^{k}{ }_{\alpha} D_{t}^{\alpha-k-1} f(\mathrm{t})\right|_{\mathrm{t}-0} \\
L\left\{{ }_{\alpha} \mathrm{D}_{t}^{\alpha} \mathrm{f}(\mathrm{t})\right\}=\mathrm{s}^{\alpha} F(\mathrm{~s})
\end{gathered}
$$

Linear fractional-order differential Eq. 4 are also represented the FO linear dynamic scheme as:

$$
\begin{aligned}
& a_{m} D_{t}^{\alpha m} y(\mathrm{t})+\mathrm{a}_{m-1} D_{t}^{\alpha m-1} y(\mathrm{t})+\ldots . .+\mathrm{a}_{1} D_{t}^{\alpha_{1}} y(\mathrm{t})+\mathrm{a}_{0} D_{t}^{\alpha_{0}} y(\mathrm{t}) \\
& =b_{l} D_{t}^{\beta l} \mathrm{u}(\mathrm{t})+b_{l-1} D_{t}^{\beta l-1} \mathrm{u}(\mathrm{t})+\ldots . .+b_{1} D_{t}^{\beta_{1}} \mathrm{u}(\mathrm{t})+b_{0} D_{t}^{b_{0}} \mathrm{u}(\mathrm{t})
\end{aligned}
$$

Take the Laplace transform of Eq. 5 with initial conditions zero.

$$
G(\mathrm{~s})=\frac{b_{l} s^{\beta l}+b_{l-1} s^{\beta l-1}+\ldots . .+b_{1} s^{\beta_{1}}+b_{0} s^{b_{0}}}{a_{m} s^{\alpha m}+\mathrm{a}_{m-1} s^{\alpha m-1}+\ldots .+\mathrm{a}_{1} s^{\alpha_{1}}+\mathrm{a}_{0} s^{\alpha_{0}}}
$$

\subsection{PID Controller}

The generating signal for PID controller contains the proportional integral derivative error signal. The TF illustration of PID controller shows in Eq. 7 [16].

$$
G_{c}(\mathrm{~s})=\mathrm{K}_{p}+K_{i} s+K_{d} s
$$

The PID controller have three parameters such as $\mathrm{Kp}$, $\mathrm{K}_{\mathrm{I}}$ and $\mathrm{K}_{\mathrm{D}}$ as proportional, integral and derivative error control schedules as shown in Figure 2. Then the constancy of the system and dissolute responses are desired. The PID controller of PS and the structure of optimization using the EHO technique [17].

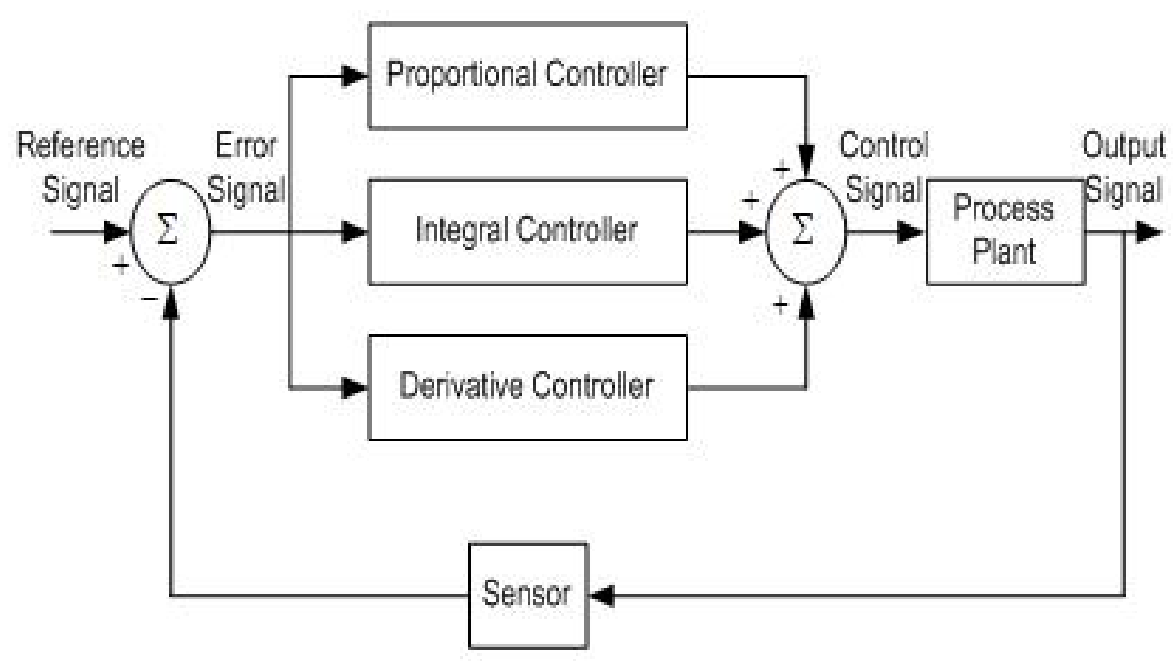

Figure 2. Block diagram of Conventional PID Controller 


\subsection{FOPID Controller}

$$
G_{c}(\mathrm{~s})=K_{P}+K_{I} \frac{s}{\lambda}+K_{D} s^{\mu}
$$

One of the most appropriate controllers is the PID controller that the main applications of the industrial. FOPID controller has two extra parameters such as derivative $(\boldsymbol{\lambda})$ and integrator $(\boldsymbol{\mu})$, This controller is called the PI $\lambda \mathrm{D} \boldsymbol{\mu}$ controller. Hence, the difference between the FOPID and PID controller is the instruction of calculus operatives that make more degree of liberty and flexibility in strategy shows in Figure $3[16,18]$.

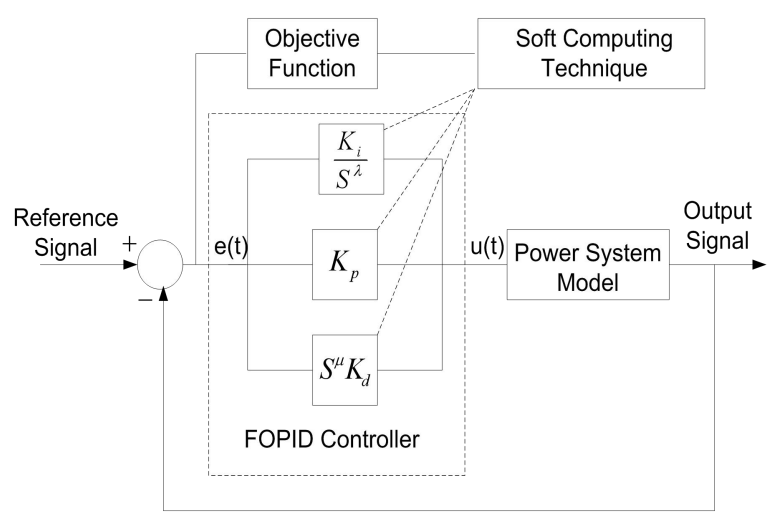

Figure 3. FOPID controller

Where, the $\mathrm{K}_{\mathrm{P}}, \mathrm{K}_{\mathrm{I}}$ and $\mathrm{K}_{\mathrm{D}}$ are proportional, integral and differential gains and the $\mu$ and $\lambda$ are fractional order of derivative and integrator. The shown in figure of FOPID controller is given below.

\subsection{Objective Function}

The objective function denoted the integral of squared error. The procedure to control unidentified parameters of the FOPID controller $\left(K_{P}, K_{I}, K_{D}, \lambda\right.$ and $\mu$ ) are also considered the optimization problem. This problem is also measured as minimized the error signal in ISE Eq. 9 [2]. The plot of the fitness function during the optimization in terms of iteration count is shown in Figure 5. These parameters are also upper and lower limits with the FPA. $K_{P}$ (primary) $\leq K_{P} \leq K_{P}$ (Last), $K_{I}$ (primary) $\leq K_{I} \leq K_{I}$ (Last), $K_{D}$ (primary) $\leq K_{D} \leq K_{D}$ (Last), $\lambda$ (Primary) $\leq \lambda \leq \lambda$ (Last) and $\mu$ (Primary) $\leq \mu \leq$ $\mu$ (Last).

$$
J=\int_{0}^{t_{\text {sim }}}(\Delta \mathrm{f})^{2} d t
$$

\section{Flower Pollination Algorithm (FPA)}

\subsection{Pollination}

The reproduction in flower happens by a combination of the gametes. It is vital that the pollinators be transported to the stigma for the combination. The dissimilar parts of the pollinators are also produced by male gametes of the female. This phenomenon of pollination is basically facilitated. There are two basic ways of pollen [11]. Such as self-pollination and cross-pollination.

FPA is a soft computing technique which is inspired by the rational way and it copies the main pollination behaviour as in flowering plants.

There are mainly four basic rules by yang in 2012, there are:

- The rule first- Pollination carry the pollen-based by flights, in Global pollen and it involves both the pollen biotic and Cross-pollination.

- Rule second- Self-pollination and biotic pollination are also involved in local pollen.

- Rule third- Flower constancy can be defined as reproduction probability which is proportional to the similarity between two flowers

- Rule fourth- Switch probability $P \varepsilon(0,1)$ can be controlled between local pollination.

Global pollen due to some external factors such as wind. Local pollen has a significant fraction in overall pollination activities to show with exemplifying the mechanism of FPA based in there four rules [12].

\subsection{Global Search of FPA}

Biotic pollen can also be done by long-distance by pollination such as birds and bats the rule first and rule third can be derived as in Eq. 10 [11]:

$$
x_{i}^{t+1}=x_{i}^{t}+L\left(\mathrm{~g}^{*}-\mathrm{x}_{i}^{t}\right)
$$

Where, $X_{\mathrm{it}}=$ the pollen or solution vector at iteration $\mathrm{t}$ and $g^{*}$ is the best solution ' $\mathrm{L}$ ' is defined as the strength of pollination. Become pollinators move at a very distance with different periods, the Levy can as significant simulators for this ' $\mathrm{L}$ ' can draw form a Levy distribution as follows in Eq. 11 [11].

$$
L \approx \frac{\lambda \Gamma(\lambda) \sin (\pi \lambda / 2)}{\pi} \frac{1}{s^{1+\lambda}},(\mathrm{s}<0)
$$

Where $\Gamma(\lambda)$ denoted the normal gamma function and this distribution is legal for large steps $\mathrm{S}>0$.

\subsection{The Local Search of FPA}

Wind as diffusion is the main region for abiotic pollen. In this, the Local pollination rule second and flower constancy rule third can be represented as follows in Eq. $12[11]:$

$$
x_{i}^{t+1}=x_{i}^{t}+\varepsilon\left(\mathrm{x}_{j}^{t}-x_{k}^{t}\right)
$$


Where Xjt and Xjk are pollen from different flowers of same plant ways. In mathematically, if $\mathrm{Xjt}$ and $\mathrm{Xjk}$ are from the same species that can be from the same population, the equation became a local random walk. If we draw from a uniform distribution in $[0,1]$ and the new way generated will not be distinct from the available solution.

\subsection{Switch Probability in FPA}

As considering both biotic and abiotic pollen, we have not considered the percentage and frequency of each pollination type to make the feature similar we use a switch probability in rule 4 where $\mathrm{P}$ determines whether solution modification leads to Local or Global Pollen Levy value of $\mathrm{P}=0.5$ can be used that more actual and effective value of $\mathrm{P}=0.8$ and gives better results with implantation. These imp three steps are shown in FPA code shows in technique first [12].

\subsection{Implementation of FPA}

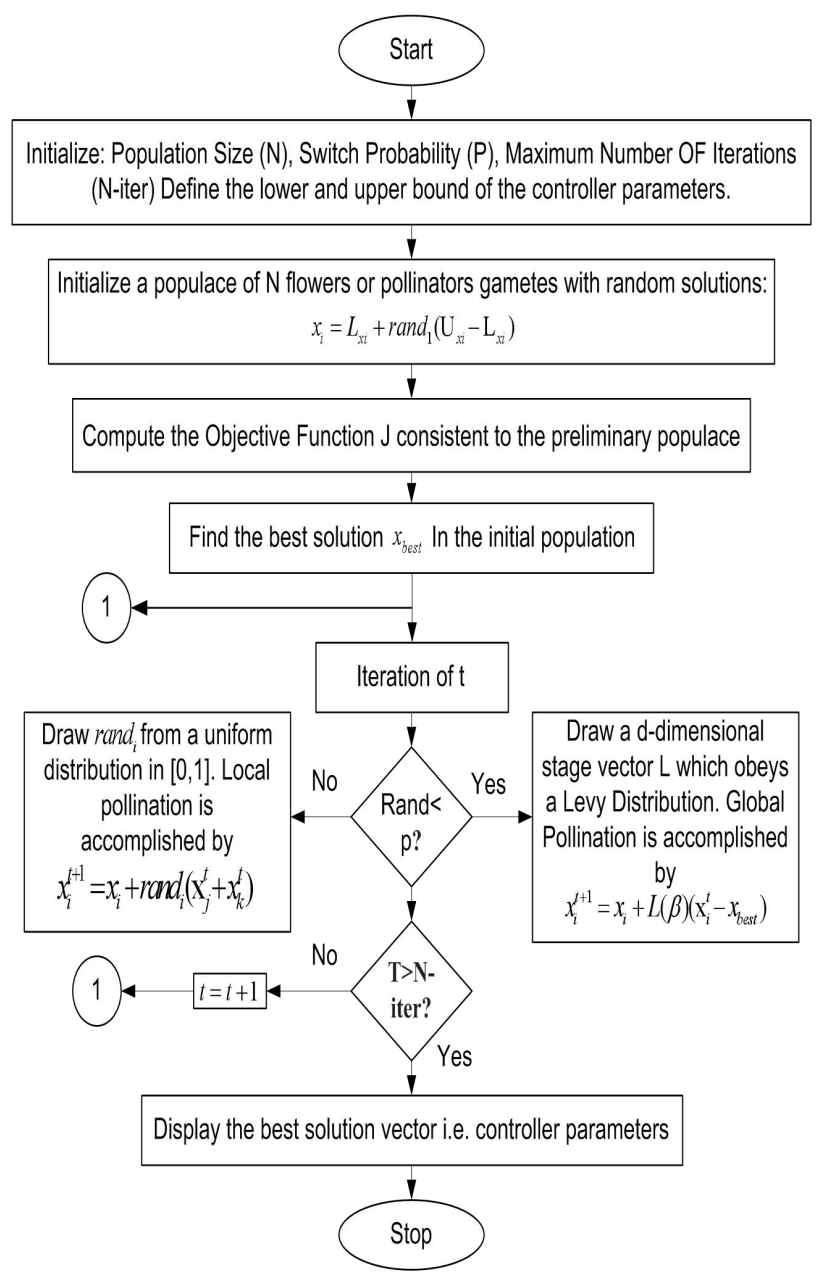

Figure 4. Flowchart of FPA

The FPA flowchart is denoted in Figure 4 [19]. The flowers positions have measured the solutions of specified problems. The applications like image compression multi-objective optimization and graph colouring multiple pollen gametes a signed to each flower and multiple flowers are assigned to each flower can be advantages schemes like flower constancy may be possible design extension simple formula is implemented for this consistency certain problems requires exotic form, though the extensive simulation is needed for exact improvement.

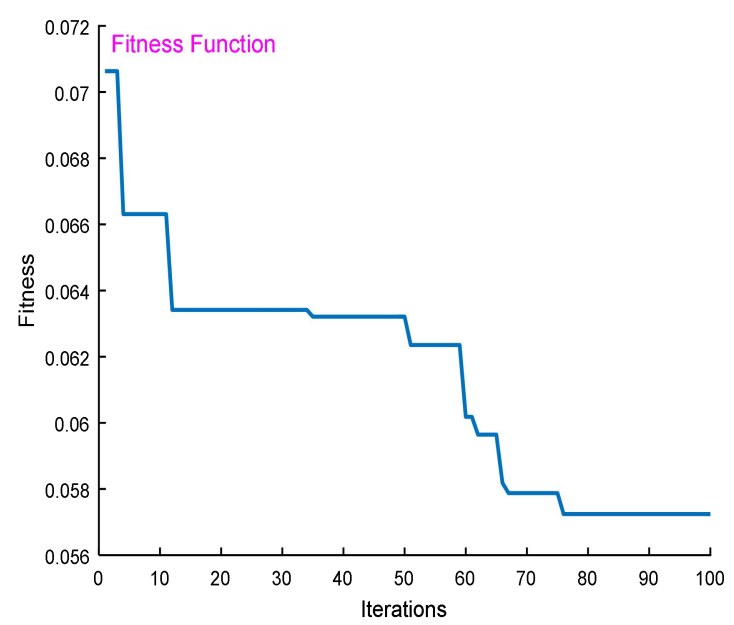

Figure 5. Convergence characteristics of FPA-FOPID controller

\subsection{Application of FPA}

When we accessible several variants of FPA, we have a drawn their application in various ranges of real-world setup. Here we temporarily represented other application problems, wireless sensor networking, clustering and organization, indication and processing shown in Figure 6.

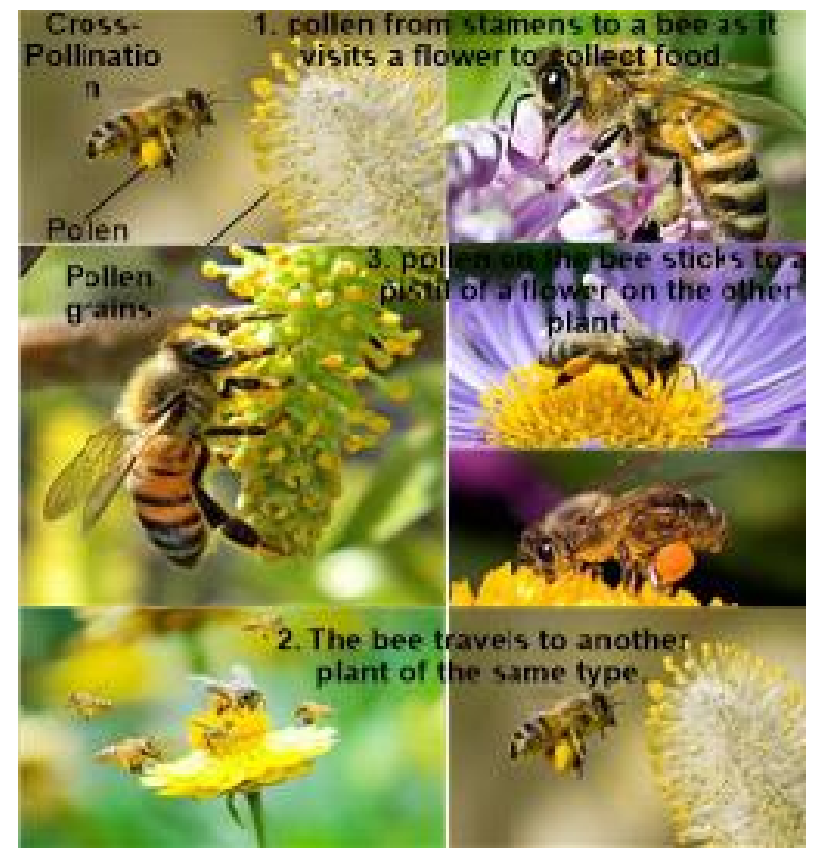

Figure 6. Flower pollination by honey bee 


\section{Simulation and Discussion}

In the simulation study, we simulate the three-area LFC with FOPID controller using FPA. The parameter of the TF used in the model is shown in Table 1. The optimization process to tune the FOPID parameters is considered with objective function as in Eq. 9 [2]. The optimal parameters using FPA and in literature are shown in Table 2. The step response comparison is included in
Table 3.

The model of Three-area Power plant using FOPID controller for LFC tuned by FPA technique is configured in MATLAB / SIMULINK stage. The pollen can be arising at both rules, i.e. Global and Local pollination but flower position is additional likely be pollinators. A switch is employed to emulate to shift between both of pollen.

Table 1. Three Area Power System Parameters

\begin{tabular}{|c|c|c|c|c|c|}
\hline Non-reheat & & Reheat & & Hydraulic & \\
\hline M1(p.u.s) & 10 & M2(p.u.s) & 10 & M3(p.u.s) & 6 \\
\hline D1(p.u./Hz) & 1 & D2(p.u./Hz) & 1 & D2(p.u./Hz) & 1 \\
\hline $\operatorname{Tch} 1(\mathrm{~s})$ & 0.3 & $\operatorname{Tch} 2(\mathrm{~s})$ & 0.3 & $\operatorname{Tch} 3(\mathrm{~s})$ & 0.2 \\
\hline TG1(s) & 0.1 & Fhp & 0.3 & $\operatorname{Tr}(\mathrm{s})$ & 5 \\
\hline R1(Hz/p.u) & 0.05 & R2(Hz/p.u) & 0.05 & R3(Hz/p.u) & 0.05 \\
\hline B1(p.u /Hz) & 21 & B2(p.u /Hz) & 21 & B3(p.u /Hz) & 21 \\
\hline \multirow[t]{3}{*}{ T1(p.u /rad) } & 22.6 & $\mathrm{~T} 2(\mathrm{p} . \mathrm{u} / \mathrm{rad})$ & 22.6 & T3(p.u /rad) & 22.6 \\
\hline & & TG2(s) & 0.2 & $\operatorname{Tw}(\mathrm{s})$ & 1 \\
\hline & & $\operatorname{Trh}(\mathrm{s})$ & 7 & $\operatorname{Rt}(\mathrm{Hz} / \mathrm{p} . \mathrm{u})$ & 0.38 \\
\hline
\end{tabular}

Table 2. Three Area Controller Parameters

\begin{tabular}{|c|c|c|c|c|c|c|}
\hline Technique & & $\mathrm{K}_{\mathrm{P}}$ & $\mathrm{K}_{\mathrm{I}}$ & $\mathrm{K}_{\mathrm{D}}$ & $\boldsymbol{\lambda}$ & $\boldsymbol{\mu}$ \\
\hline \multirow{3}{*}{ Proposed } & Area 1 & -0.3728 & -0.1482 & -0.5987 & 0.9954 & 0.4397 \\
\cline { 2 - 7 } & Area 2 & -0.6500 & -0.1896 & -0.8146 & 1.3610 & 1.5000 \\
\cline { 2 - 7 } & Area 3 & 0.5100 & -0.9000 & 0.6000 & 0.7000 & 0.5101 \\
\hline \multirow{3}{*}{ Taher, 2013 [13] } & Area 1 & 0.6700 & -0.4006 & -0.9910 & 1 & 0.6543 \\
\cline { 2 - 7 } & Area 2 & -0.3266 & -0.2946 & -1 & 1 & 0.8650 \\
\cline { 2 - 7 } & Area 3 & -1 & -1 & 0.4888 & 0.6762 & 0.5686 \\
\hline \multirow{3}{*}{ Bayati, 2015 [14] } & Area 1 & -0.3287 & -0.584 & -0.739 & 0.9246 & 0.6698 \\
\cline { 2 - 7 } & Area 2 & -0.7575 & -0.139 & -0.97 & 0.9944 & 0.9863 \\
\cline { 2 - 7 } & Area 3 & -0.1528 & -1 & 0.5853 & 0.643 & 0.962 \\
\hline
\end{tabular}

Table 3. Comparative Performance of Settling Time and Undershoot

\begin{tabular}{|c|c|c|c|c|c|c|}
\hline \multirow{2}{*}{ Parameter } & \multicolumn{2}{|c|}{$\Delta f_{1}$} & \multicolumn{2}{c|}{$\Delta f_{2}$} & \multicolumn{2}{c|}{$\Delta f_{3}$} \\
\hline & Settling time & Undershoot (10-3) & Settling time & Undershoot (10-3) & Settling time & Undershoot (10-3) \\
\hline Proposed & 34.891 & -0.086 & 34.417 & -0.088 & 34.891 & -0.088 \\
\hline Taher, 2013 [13] & 26.676 & -0.097 & 27.326 & -0.104 & 26.262 & -0.111 \\
\hline Bayati, 2015 [14] & 24.693 & -0.087 & 25.546 & -0.092 & 22.545 & -0.102 \\
\hline
\end{tabular}

Table 4. Comparative Performance of Settling Time and Undershoot

\begin{tabular}{|c|c|c|c|c|}
\hline Parameter & \multicolumn{2}{|c|}{$\Delta P_{\text {tiel }}$} & \multicolumn{2}{c|}{$\Delta P_{\text {tiez }}$} \\
\hline & Settling time & Undershoot (10-3) & Settling time & Undershoot (10-3) \\
\hline Proposed & 34.283 & -0.088 & 34.891 & -0.088 \\
\hline Taher, 2013 [13] & 27.404 & -0.104 & 26.299 & -0.111 \\
\hline Bayati, 2015 [14] & 25.394 & -0.093 & 22.393 & -0.102 \\
\hline
\end{tabular}


The demonstration of three area generating units using FPA tuned FOPID controller with overhead works FOPID controller in the result is $1 \%$ of step load perturbation. It is also applied to the power demand in non-reheat thermal, reheat thermal and hydraulic thermal plant for the power system. The controller has demonstrated the toughness of the system to variation in the operational state and the system parameters diverse within the limit $+25 \%$ to $-25 \%$.

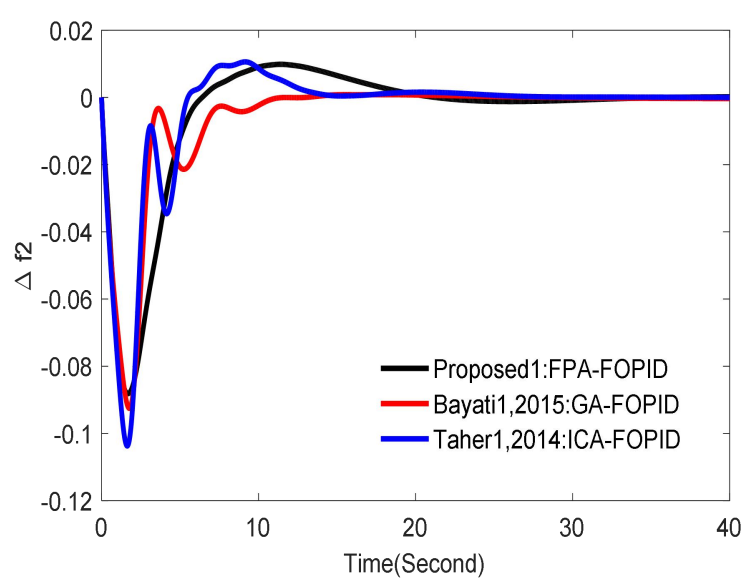

Figure 7. Change in the frequency of area 2 for step increase in the demand for area 2

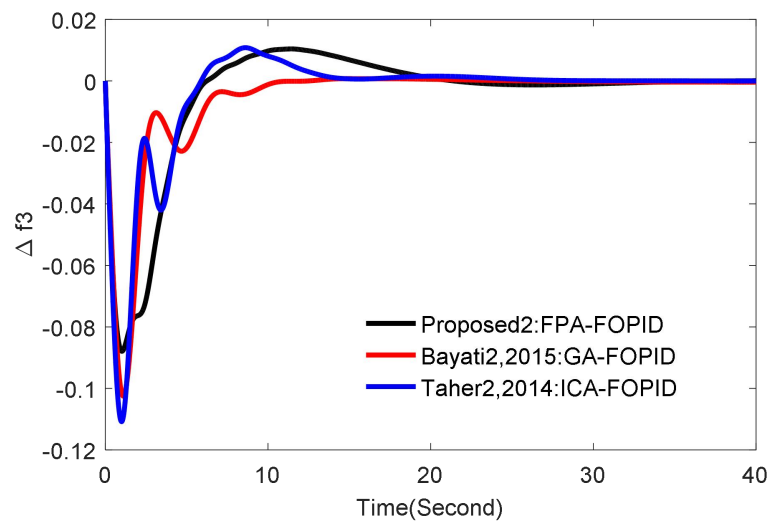

Figure 8. Change in the frequency of area 3 for step increase in demand of area 3 .

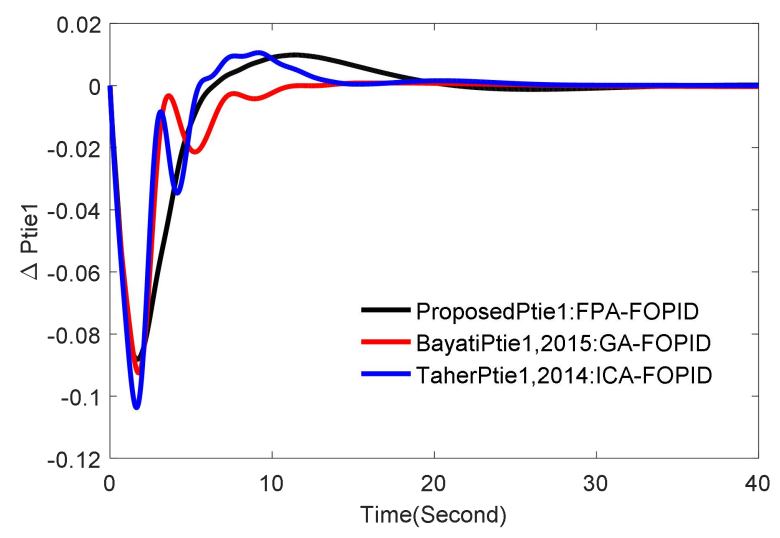

Figure 9. Change in Ptie1

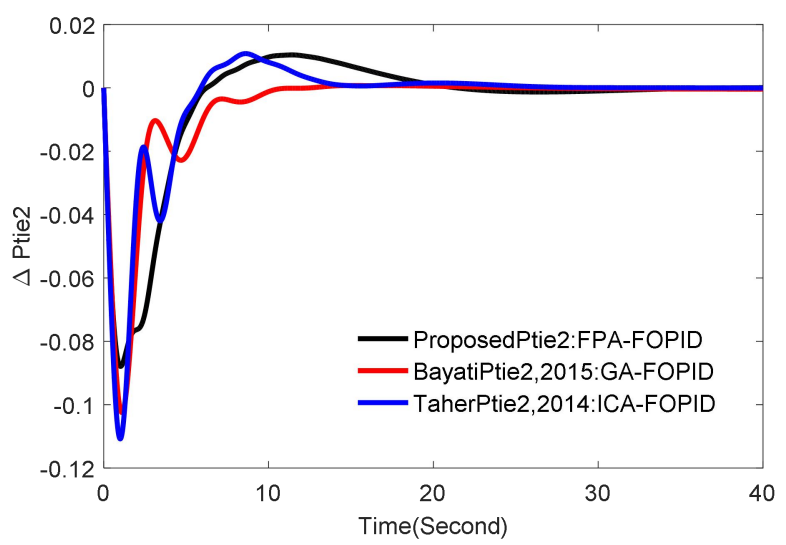

Figure 10. Change in Ptie2

\subsection{Performance Comparison}

A three area generating units is considered for load frequency control problems. A $1 \%$ step load agitation is given to the load demand. The FOPID controller for FPA gives less undershoot of $\Delta f_{1}=-0.086 * 10-3$, $\Delta f_{2}=\Delta f_{3}=\Delta P_{\text {tiel }}=\Delta P_{\text {tie } 2}=-0.088 * 10-3$ where the undershoot of taher and bayati are $\Delta f_{1}=-0.097$, $\Delta f_{2}=-0.104, \Delta f_{3}=-0.111, \Delta P_{\text {tiel }}=-0.104, \Delta P_{\text {tie } 2}=-0.111$, $\Delta f_{1}=-0.087, \Delta f_{2}=-0.092, \Delta f_{3}=-0.102, \Delta P_{\text {tie } 1}=-0.093$, $\Delta P_{\text {tie } 2}=-0.102$. The proposed undershoot values give the better result are compared the Taher and Ayati. Comparison of frequency eccentricity on the source of undershoot and settling time tabulated in Table 4. The FPA-FOPID controller gives less undershoot as compared to the published paper by considered their FOPID parameters. The FPA-FOPID controller responses for LFC compared other tuned FOPID controller.

\section{Conclusions}

In this article, the FOPID for an LFC is set onward in a three-area power system using FPA. The FOPID controller parameters are also tuned by FPA for solving the LFC problem to minimize the change in frequency of three-area generating units. Simulation of comparative cases that the proposed controller to improve the dynamic responses in another FOPID controller. The dominance and robustness of proposed FOPID controller, results are compared with FOPID controller. The parameters of the improvement for FPA based FOPID controllers essential not to be a variation even if the parameters are too extensive dissimilarity in loading condition. The simulation results demonstrate that the proposed FOPID 
controller gives better performances. The undershoot is reduced by the proposed FOPID controller tuned by the FPA as compared to the controller.

\section{REFERENCES}

[1] D. K. Sambariya and R. Fagna, "Load Frequency Control of Multi-Area Hydro Thermal Power System Using Elephant Herding Optimization Technique " in Journal of Automation and Control, Vol. 5 no. 1, 2017 pp. 25-36

[2] D. Sambariya and R. Fagna, "A novel Elephant Herding Optimization based PID controller design for Load frequency control in power system," in Computer, Communications and Electronics (Comptelix), 2017 International Conference on, 2017, pp. 595-600.

[3] D. Sambariya and R. Fagna, "A robust PID controller for load frequency control of single area re-heat thermal power plant using elephant herding optimization techniques," in Information, Communication, Instrumentation and Control (ICICIC), 2017 International Conference on, 2017, pp. 1-6.

[4] H. Shayeghi, A. Molaee, K. Valipour, and A. Ghasemi, "Multi-source power system FOPID based Load Frequency Control with high-penetration of Distributed Generations," in 2016 21st Conference on Electrical Power Distribution Networks Conference (EPDC), 2016, pp. 131-136.

[5] A. S. Chopade, S. W. Khubalkar, A. Junghare, M. Aware, and S. Das, "Design and implementation of digital fractional order PID controller using optimal pole-zero approximation method for magnetic levitation system," IEEE/CAA Journal of Automatica Sinica, vol. 5, no. 5 pp.977-989, 2018.

[6] J. Morsali, K. Zare, and M. T. Hagh, "Applying fractional order PID to design TCSC-based damping controller in coordination with automatic generation control of interconnected multi-source power system," Engineering Science and Technology, an International Journal, vol. 20, pp. 1-17, 2017.

[7] R. Pradhan, P. Patra, and B. Pati, "Comparative studies on design of fractional order proportional integral differential controller," in Advances in Computing, Communications and Informatics (ICACCI), 2016 International Conference on, 2016, pp. 424-429.

[8] S. Debbarma, L. C. Saikia, and N. Sinha, "Automatic generation control of multi-area system using two degree of freedom fractional order PID controller: a preliminary study," in Power and Energy Engineering Conference (APPEEC), 2013 IEEE PES Asia-Pacific, 2013, pp. 1-6.

[9] R. Gupta and S. Gairola, "FOPID controller optimization employing PSO and TRSBF function," in Recent Advances in Engineering \& Computational Sciences (RAECS), 2015 2nd International Conference on, 2015, pp. $1-6$.
[10] M. Chiranjeevi and V. S. G. Lakshmi, "Design of PSO based Fractional order Load Frequency controller for two area power system." in IOSR Journal of Electrical and Electronics Engineering Vol-9 Issue -1 pp.67-74, 2014

[11] X.-S. Yang, "Flower pollination algorithm for global optimization," in International conference on unconventional computing and natural computation, 2012, pp. 240-249.

[12] [Z. A. A. Alyasseri, A. T. Khader, M. A. Al-Betar, M. A. Awadallah, and X.-S. Yang, "Variants of the Flower Pollination Algorithm: A Review," in Nature-Inspired Algorithms and Applied Optimization, ed: Springer, 2018, pp. 91-118.

[13] S. A. Taher, M. H. Fini, and S. F. Aliabadi, "Fractional order PID controller design for LFC in electric power systems using imperialist competitive algorithm," Ain Shams Engineering Journal, vol. 5, pp. 121-135, 2014.

[14] N. Bayati, A. Dadkhah, B. Vahidi, and S. H. H. Sadeghi, "FOPID Design for Load-Frequency Control Using Genetic Algorithm," Science International, vol. 27, 2015.

[15] J. Viola and L. Angel, "Design and statistical robustness analysis of FOPID, IOPID and SIMC PID controllers for the control of an input-output linearized plant model," in Automatic Control (CCAC), 2015 IEEE 2nd Colombian Conference on, 2015, pp. 1-6.

[16] M. I. Alomoush, "Load frequency control and automatic generation control using fractional-order controllers," Electrical Engineering (Archiv fur Elektrotechnik), vol. 91, pp. $357-368,2010$.

[17] S. K. Verma, S. Yadav, and S. K. Nagar, "Optimal fractional order PID controller for magnetic levitation system," in Systems Conference (NSC), 2015 39th National, 2015, pp. 1-5.

[18] P. N. Topno and S. Chanana, "Application of tilt integral derivative control on two-area power system," Journal of Engineering Research, vol. 4, p. 12, July 232016.

[19] S. Debbarma and A. Dutta, "Utilizing electric vehicles for LFC in restructured power systems using fractional order controller," IEEE Transactions on Smart Grid, 2016. 